\title{
A new device used in the restoration of kinematics after total facet arthroplasty
}

This article was published in the following Dove Press journal:

Medical Devices: Evidence and Research

29 May 2014

Number of times this article has been viewed

\section{Vermesan' \\ R Prejbeanu' \\ CVlad Daliborca' \\ H Haragus' \\ M Magureanu ${ }^{2}$ \\ M Marrelli ${ }^{3-5}$ \\ L Promenzio ${ }^{4}$ \\ M Caprio ${ }^{6}$ \\ R Cagiano,** \\ M Tatullo ${ }^{3,5, *}$ \\ 'Victor Babeș University of Medicine and Pharmacy, Timisoara, ${ }^{2}$ Carol Davila University of Medicine and Pharmacy, Bucharest, Romania; ${ }_{3}^{3}$ Maxillofacial Unit, Dental Center Calabrodental, ${ }^{4}$ Orthopedics and Traumatology Unit, Marrelli Hospital, ${ }^{5}$ Biomedical Section, Tecnologica Research Institute, Crotone, ${ }^{6}$ Department of Biomedical Sciences and Human Oncology, Medical Faculty, Aldo Moro University of Bari, Bari, Italy \\ *These authors contributed equally to this work}

Correspondence: R Cagiano Department of Biomedical Sciences and Human Oncology, Medical Faculty, Aldo Moro University of Bari, I Piazza Umberto I, Bari 70I2I, Italy

Email raffaele.cagiano@uniba.it

\begin{abstract}
Facet degeneration can lead to spinal stenosis and instability, and often requires stabilization. Interbody fusion is commonly performed, but it can lead to adjacent-segment disease. Dynamic posterior stabilization was performed using a total facet arthroplasty system. The total facet arthroplasty system was originally intended to restore the natural motion of the posterior stabilizers, but follow-up studies are lacking due to limited clinical use. We studied the first 14 cases (long-term follow-up) treated with this new device in our clinic. All patients were diagnosed with lumbar stenosis due to hypertrophy of the articular facets on one to three levels (maximum). Disk space was of normal height. The design of this implant allows its use only at levels L3-L4 and L4-L5. We implanted nine patients at the L4-L5 level and four patients at level L3-L4. Postoperative follow-up of the patients was obtained for an average of 3.7 years. All patients reported persistent improvement of symptoms, visual analog scale score, and Oswestry Disability Index score. Functional scores and dynamic radiographic imaging demonstrated the functional efficacy of this new implant, which represents an alternative technique and a new approach to dynamic stabilization of the vertebral column after interventions for spine decompression. The total facet arthroplasty system represents a viable option for dynamic posterior stabilization after spinal decompression. For the observed follow-up, it preserved motion without significant complications or apparent intradisk or adjacent-disk degeneration.
\end{abstract}

Keywords: lumbar stenosis, dynamic facet arthroplasty, dynamic stabilization, vertebral fusion

\section{Introduction}

Lower-back pain has a high incidence and prevalence among older adults. Furthermore, the most frequent indication for surgery is spinal stenosis. ${ }^{1}$ After decompression (laminectomy or foraminotomy), the structural integrity of the lumbar spine can be weakened, and requires additional support. This is achieved by vertebral fusion, which is the current standard for outcome and the most commonly used procedure. Interbody arthrodesis can be performed through anterior, lateral, posterior, or transforaminal approaches. The vertebral disks are replaced with bone to promote arthrodesis, the sagittal height is restored with cages, and supplemental stabilization is completed by internal fixation using transpedicular instrumentation. The result is a bloc of vertebral segments that are permanently fixed and rigid. This resolves the immediate situation, but in the long term the proximal segment is overloaded, which might aggravate the degeneration, lead to hypermobility and osteophyte formation, become symptomatic, and require further surgery. ${ }^{2}$ This phenomenon is inherent to the principle of fusion and cannot be avoided, with an annual incidence of $2.5 \%$ and an estimated 10 -year 
prevalence of $22.2 \%{ }^{3}$ The increased stresses on the adjacent disk and facets might be dependent on the rigidity of the stabilization. ${ }^{4}$

In such circumstances, the need for an implant that will allow for dynamic stabilization is paramount. These were the premises that led to the introduction of the total facet arthroplasty system, aimed at restoring normal segmental kinematics. Dynamic stabilization was not a new idea, ${ }^{5,6}$ but facet arthroplasty was designed to mimic natural movement of the vertebral segments without overstraining the adjacent vertebral disks, which was not possible before. ${ }^{7,8}$

\section{Materials and methods}

We performed a prospective observational study on 14 cases operated on in our department between 2005 and 2008. The patients were diagnosed with lumbar stenosis due to hypertrophy of the articular facets on one to three levels. Dynamic posterior stabilization was performed using the Total Facet Arthroplasty System (Archus Orthopedics, Redmond, WA, USA) (Figure 1). The implant could only be used at the L3-L4 and L4-L5 levels. We therefore implanted nine at L4-L5 and four at L3-L4 (see Figure 2 and Tables 1-3). For all cases, the disk spaces were at least $75 \%$ of normal height. Postoperative follow up was obtained for an average of 3.7 years.

Necessary criteria to consider the patient suitable for this implant were:

- degenerative spinal stenosis, lateral or central, at L3-L4 and/or L4-L5 levels, with imaging confirmation through at least one of computed tomography, magnetic resonance imaging, X-ray, and myelography, which can show:

- compression on cauda equina, dural sac, or roots

- impingement on nerve roots due to bony or soft-tissue elements

- hypertrophic facets with lateral or central compression

- in cases of spondylolisthesis, at the level proposed for this new implant, the grade of severity should be no greater than grade I

Table I List of most frequent clinical symptoms in our study group

\begin{tabular}{ll}
\hline Symptoms & Incidence \\
\hline Lumbar pain & $76 \%$ \\
Neurological claudication & $46 \%$ \\
Muscular weakness & $54 \%$ \\
Paresthesia, numbness & $30 \%$ \\
Pain radiated to lower limbs & $92 \%$ \\
\hline
\end{tabular}

Table 2 List of the imaging investigations performed for diagnosis, surgery, follow-up evaluation, and implant indication for treatment in our study group

\begin{tabular}{ll}
\hline Type of investigation & Use \\
\hline X-ray lumbar vertebrae & $100 \%$ \\
Myelography & $18 \%$ \\
Myelo-CT & $18 \%$ \\
NMR & $100 \%$ \\
EMG & $21 \%$ \\
\hline
\end{tabular}

Abbreviations: $\mathrm{CT}$, computed tomography; NMR, nuclear magnetic resonance; EMG, electromyography.

- neurogenic claudication - thigh or leg discomfort, pain, paresthesia, muscular weakness, fatigue, sensation of heaviness around the leg, pain in the medial thigh and lumbar region, tingling sensation that can be worsened by walking or by orthostatism and relieved with rest or lying down on a bed

- age between 40 and 80 years

- patients who have been referred for laminectomy due to spinal stenosis up to a maximum L3.

Exclusion criteria (patients not suitable for this implant) were:

- patients under 40 years or over 80 years of age

- spondylolisthesis of grade II or more and retrolisthesis at the proposed level for the implant

- more than three levels proposed for the laminectomy

- levels other than L3-L5.

The implant is manufactured using the most recent technology with a variable geometry, which allows an exact choice of angles and dimensions in order to reproduce the intervertebral movements perfectly. Biomechanical tests performed during our study demonstrated that this implant allows relatively normal flexion and extension of the involved vertebrae, as shown in Figures 1 and 2.

The new implant is made up of eleven modular components:

- two superior curved rods

- two inferior rods to which the connectors are adapted

- a transverse rod with two cups at the ends to control tracking

- two connectors.

Table 3 Distribution of spinal stenosis in our patients

\begin{tabular}{ll}
\hline Diagnosis & Incidence \\
\hline Degenerative central lumbar stenosis (eight cases) & $61 \%$ \\
Lateral or foraminal stenosis (seven cases) & $54 \%$ \\
L4-L5 spondylolisthesis associated with stenosis (one case) & $7.7 \%$ \\
L5-SI spondylolisthesis associated with stenosis (one case) & $7.7 \%$ \\
\hline
\end{tabular}




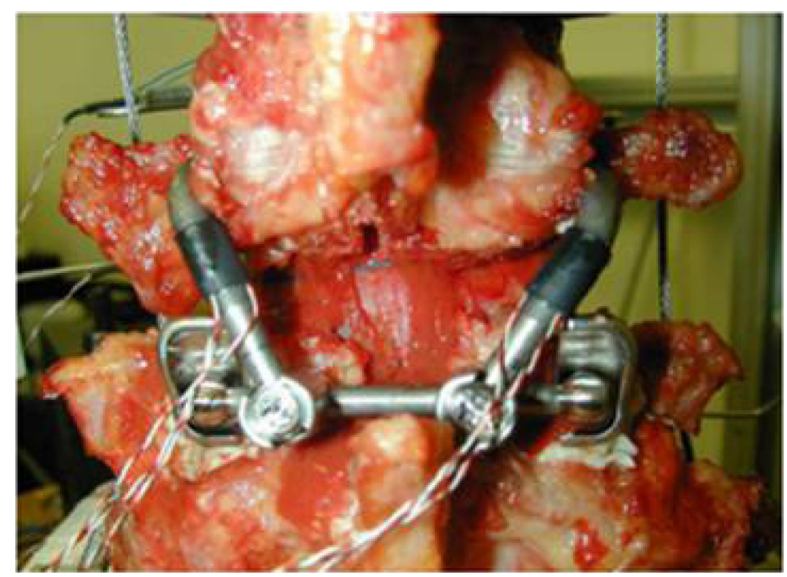

Figure I Flexion-extension movements of intact vertebrae after ligament resection, facet (zygomatic) joint removal, and stabilization with the new implant.

Tests indicated that the best way to fix the implants was with acrylic cement (Figure 3).

From biomechanical studies, the technical specifications indicated that this system resists for more than 10 million cycles, which roughly translates to flexion and extension movements for average human performance for over 10 years. The adhesion of the implant to the cement can take two to three times its maximum duty loads without debonding. This new implant can withstand more than twice the load it takes to detach a pedicle-screw fusion system (the current standard of care) from bone without loosening from the spine. The surgical procedure mostly overlaps with classical decompression. A standard posterior median approach is used, with associated laminectomy and foraminectomy for decompression. In nine cases, we performed a laminectomy at two levels, and in four cases laminectomy was performed at one and three levels. This was followed by foraminotomy and inferior-facet resection at L3 or L4 accordingly. The next step was drilling of the 2-4 mm transpedicular tunnels for application of the probes at the two levels. This allowed us to determine the angle and dimension of the implants. The final tunnels were then drilled to $6 \mathrm{~mm}$. Because this is a cemented procedure, it is very important to keep the walls intact in order to prevent extravasations of the cement into the medullary canal or along the roots.

We then assembled the desired implant size with the help of an assistant. The device is made up of eleven modular components: two superior curved rods, two inferior rods to which the connectors are attached, a transverse rod with two cups at the ends to control tracking, and two connectors. It is fixed through the pedicles to the vertebral bodies, using poly(methyl methacrylate) cement with increased barium content (same as in vertebroplasty). We first cemented the distal rods and then the proximal ones. Connections between all four elements are made with bolts, the same as used for

H1091:Flexion and extension @ 600 N

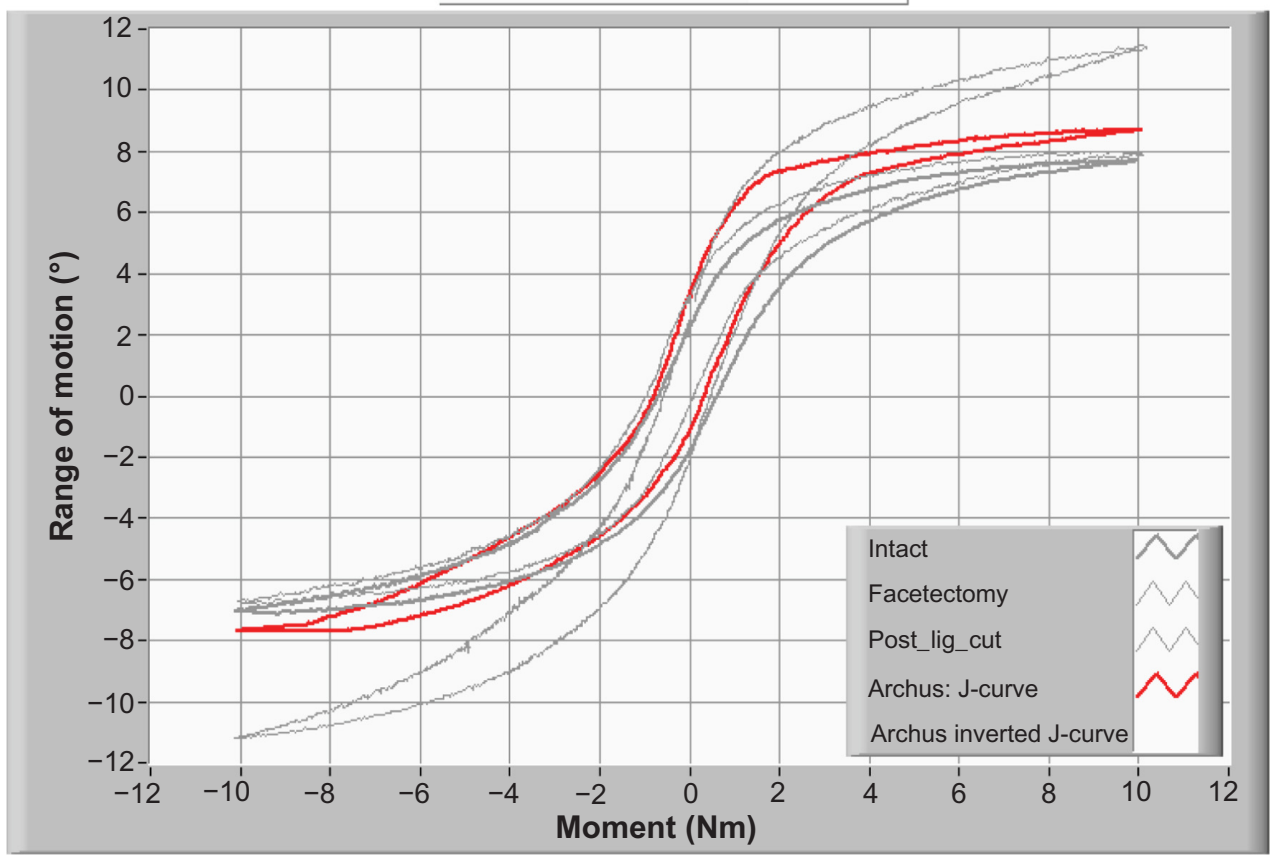

Figure 2 Range of motion for the fresh cadaver specimen shown in Figure I.

Notes: Distribution based on sex shows a preponderance for men. Distribution by age shows a slight permanent increase in men aged $60-70$ years. Mean age was 65.5 years, with floor and ceiling limits being 41 and 78 , respectively. 


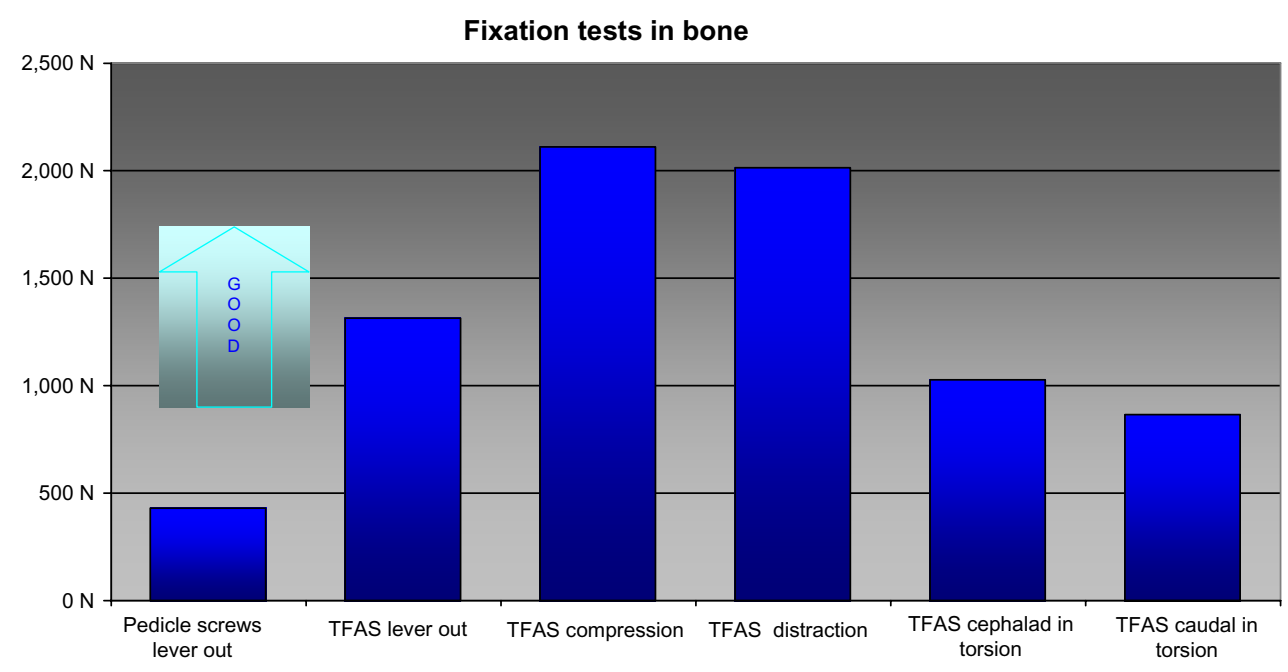

Figure 3 Data used to choose the cemented fixation.

Abbreviation: TFAS, Total Facet Arthroplasty System.

transpedicular instrumentation. It is very important that the two bolts are positioned parallel to the sliding surfaces of the distal stems. The medullary canal and the holes for conjugation were verified again, and the wound was closed with a vacuum drain.

\section{Results}

Distribution by age and sex showed a preponderance for men aged $60-70$ years. The mean age was 65.5 years, with the range being $41-78$ years. The most frequent level of decompression was L4-L5 (nine cases), followed by L3-L4 (seven cases). In nine cases, laminectomy was performed on two levels, in two cases on three levels and in two cases on only one level (Table 4). The average time necessary to perform the surgery was about 60 minutes, but with experience this might be reduced. Without complications, the patient can be mobilized within 24 hours postoperatively. There is no need to use a lumbar corset. The drain can be removed within 48 hours.

The established protocol for the follow-up period was clinical and radiological exams at 3 and 6 months and then yearly, corroborated with function and pain according to a visual analog scale and Oswestry score. We had no immediate specific postoperative complications. One patient died soon after surgery due to an associated

Table 4 Distribution based on decompressed levels

\begin{tabular}{lllll}
\hline $\begin{array}{l}\text { Decompression } \\
\text { level }\end{array}$ & LI-L2 & L2-L3 & L3-L4 & L4-L5 \\
\hline Number of cases & I & 3 & 7 & 9 \\
\hline Abbreviation: L, level. & & & &
\end{tabular}

Abbreviation: L, level. pathology. The preliminary results of the initial 20 patients have been previously presented. ${ }^{9-11}$ Of the 13 patients available for long-term follow-up, four showed progression of the degeneration, both at the operated level, as well as the proximal segment, with limited range of motion but no clinical deterioration. All patients showed clinical improvement. The majority of patients had their symptoms relieved during the first 3 months. This is important, because it allows for immediate recovery without a long period of rest waiting for consolidation, as is the case with fusion. Functional scores, together with dynamic radiographic imaging, confirmed the functional efficacy of this new implant (Table 5, Figures 4, 5, 6 and 7).

\section{Discussion}

The most important aspect of our case series is that it is one of only very few long-term reports of clinical outcomes using total facet arthroplasty. Since the procedure's conception

Table 5 Oswestry score interpretation

\begin{tabular}{lllll}
\hline Disability & Preop & $\begin{array}{l}\text { Postop } \\
\text { 3 months }\end{array}$ & $\begin{array}{l}\text { Postop } \\
\text { 6 months }\end{array}$ & $\begin{array}{l}\text { Postop } \\
\mathbf{3 . 7} \text { years }\end{array}$ \\
\hline$>$ 0\%-20\%, minimal & 0 & 3 & 6 & 6 \\
$>\begin{array}{l}\text { 20\%-40\%, } \\
\text { moderate }\end{array}$ & 0 & 5 & 5 & 6 \\
$>\begin{array}{l}\text { 40\%-60\%, } \\
\text { severe }\end{array}$ & 5 & 1 & 1 & 1 \\
$>\begin{array}{l}\text { 60\%-80\%, } \\
\text { crippled }\end{array}$ & 7 & 0 & 0 & 0 \\
$>\begin{array}{l}80 \%-100 \%, \\
\text { bedridden }\end{array}$ & 1 & 0 & 0 & 0 \\
\hline
\end{tabular}

Abbreviations: Preop, preoperation; Postop, postoperation. 


\section{Oswestry score}

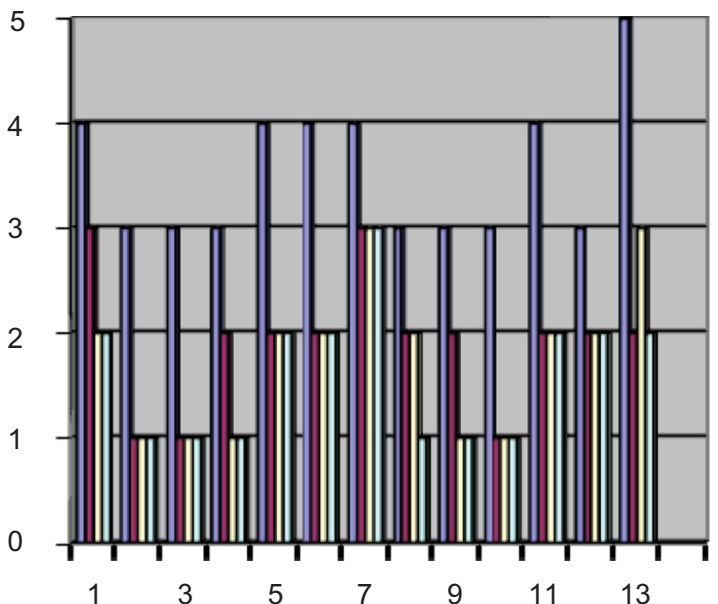

Preop

Postop 3 months

Postop 6 months

Postop 3.7 years

Figure 4 Oswestry scores.

Abbreviations: Preop, preoperation; Postop, postoperation.

and clinical use, the limited articles studying facet joint replacement focused on kinematic ${ }^{7}$ motion of the adjacent level, ${ }^{8}$ disk pressures, and load sharing. ${ }^{12}$ These experimental cadaver analyses proved conceptual validity, but long-term outcomes were uncertain.

We have presented proof of the potential validity of this system, though based on a small number of patients. The absence of a comparative control group precluded any statistical analysis. Nevertheless, all of the 13 patients available for follow-up showed the minimum clinically significant improvement in Oswestry and visual analog scales, which persisted throughout the follow-up period. ${ }^{13}$

Adjacent-segment disease does not yet have a precisely determined etiology. It can be attributed to decompression, fusion, and pedicle screw misplacement, as well as preexisting degeneration. ${ }^{14-17}$ Therefore, there is still effort being made toward improving sagittal and postural balance with better solutions for lumbar arthrodesis. $^{18}$

Currently, there are several implants on the market boasting dynamic posterior stabilization. ${ }^{5}$ The Dynesys ${ }^{\circledR}$ device (Zimmer, Warsaw, IN, USA) has received the most attention. Longitudinal imaging studies have found potential protective effects on adjacent-disk disease, especially for seriously degenerated disks. ${ }^{18}$ Biomechanical research has shown that dynamic stabilization has less overall range of motion than the intact spine. ${ }^{19}$

In addition, intradiscal pressures were altered compared to the normal disk. ${ }^{20}$ Even though dynamic stabilization distributes mobility more physiologically compared to fusion, over the cranial and caudal adjacent segments ${ }^{21}$ adjacent-disk degeneration seems to continue. ${ }^{22}$ With long-term follow-up, almost half of the patients showed some degree of progression of degeneration, but satisfaction remained very high. ${ }^{23}$

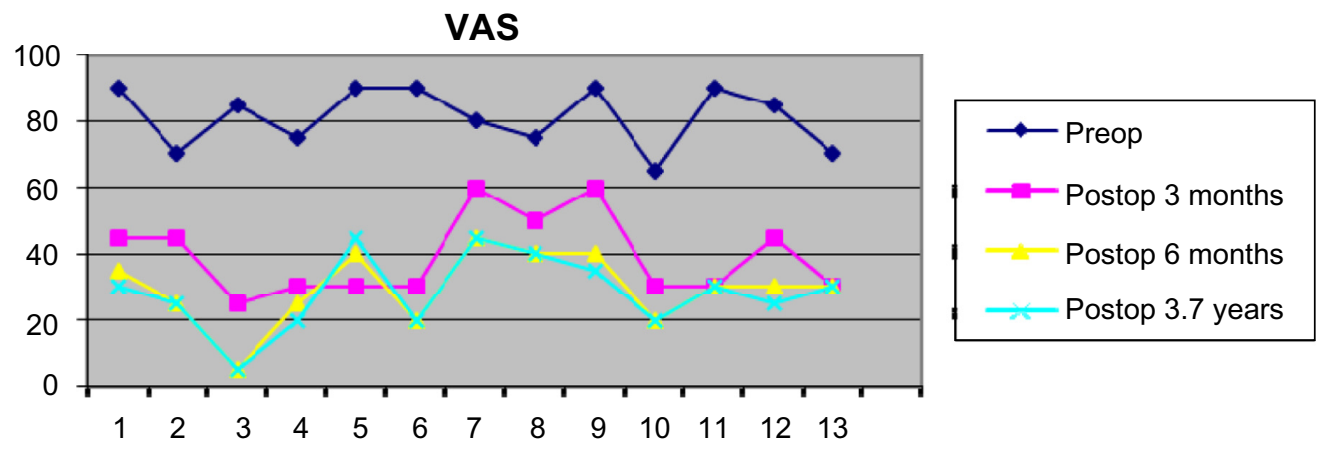

Figure 5 Visual analog scale: pre- and postoperative comparison.

Abbreviations: Preop, preoperation; Postop, postoperation; VAS, visual analog scale. 


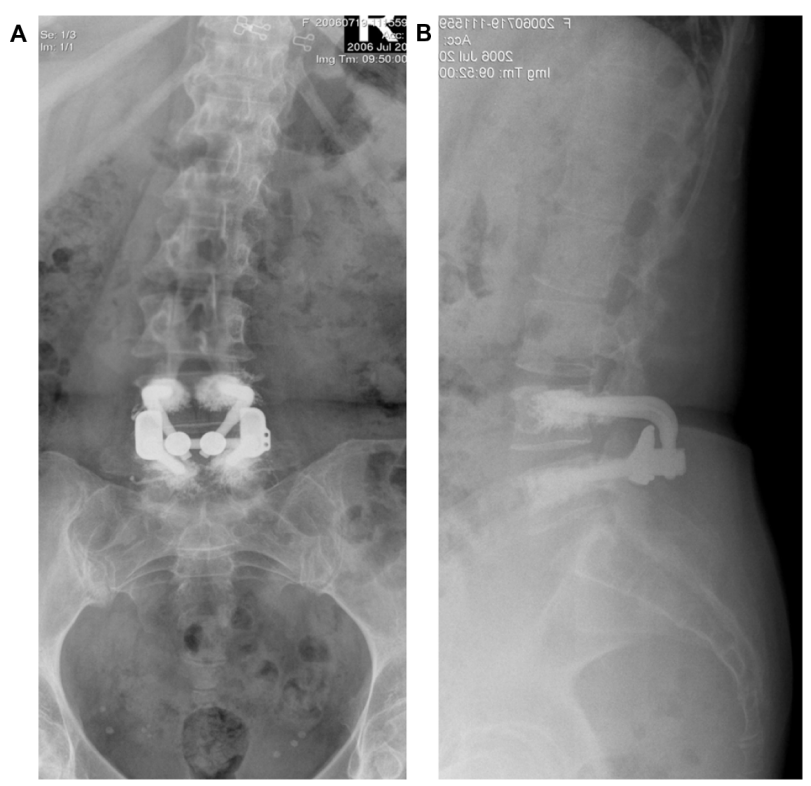

Figure 6 Lumbar X-rays with the new implant (anteroposterior and lateral standing) Note: anteroposterior (A) and lateral (B) standing.

As with our cohort, residual range of motion is reduced, as well as the need for secondary surgery. ${ }^{24}$ Yet with all favorable results, there are also reports that show inferior long-term functional and clinical outcomes compared to fusion, except for older patients, who appear to be more satisfied..$^{25}$

The cemented fixation of the pedicle screws provides great mechanical strength, especially in osteoporotic bone, and might reduce some of the complications and cyst osteolysis encountered with osteointegration. ${ }^{26,27}$ In addition, cemented fixation allows immediate movement, support, and rehabilitation, and has not yet demonstrated any adverse events.
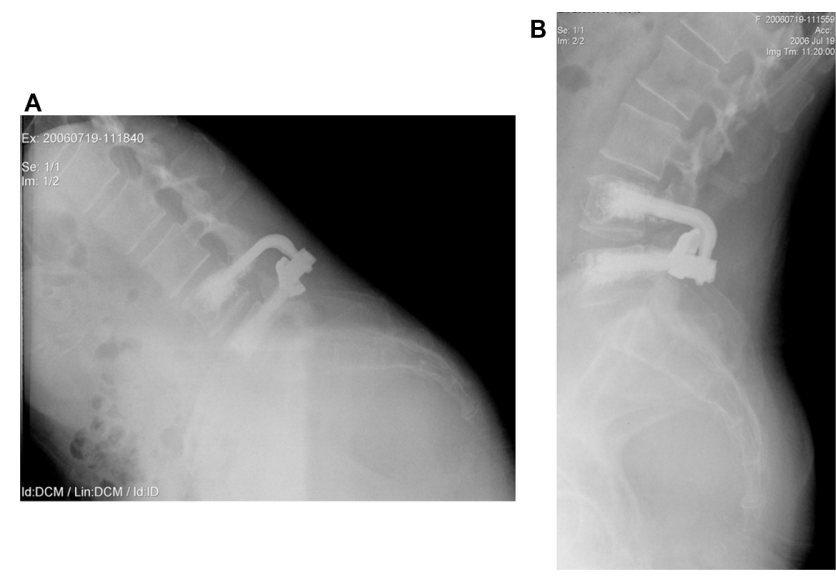

Figure 7 Lumbar $\mathrm{X}$-rays of the same case with the new implant in place. Note: flexion (A) and extension (B).

\section{Conclusion}

We can conclude that total facet arthroplasty represents a feasible long-term solution for dynamic stabilization of the lumbar spine after decompression. It also has the potential advantage of preserving normal biomechanics of the lumbar segments, which might reduce the impact of adjacent-disk degeneration.

\section{Acknowledgment}

Thanks to Dr Scott Webb for contributing to the surgical procedures and overall patient management, as well as training for the authors.

\section{Disclosure}

The authors report no conflicts of interest in this work.

\section{References}

1. Strömqvist B, Fritzell P, Hägg O, Jönsson B, Sandén B. Swespine: the Swedish spines register: the 2012 report. Eur Spine J. 2013;22(4): 953-974.

2. Chen CS, Feng CK, Cheng CK, Tzeng MJ, Liu CL, Chen WJ. Biomechanical analysis of the disc adjacent to posterolateral fusion with laminectomy in lumbar spine. J Spinal Disord Tech. 2005;18(1):58-65.

3. Sears WR, Sergides IG, Kazemi N, Smith M, White GJ, Osburg B. Incidence and prevalence of surgery at segments adjacent to a previous posterior lumbar arthrodesis. Spine J. 2011;11(1):11-20.

4. Sudo H, Oda I, Abumi K, Ito M, Kotani Y, Minami A. Biomechanical study on the effect of five different lumbar reconstruction techniques on adjacent-level intradiscal pressure and lamina strain. J Neurosurg Spine. 2006;5(2):150-155.

5. Mulholland RC, Sengupta DK. Rationale, principles and experimental evaluation of the concept of soft stabilization. Eur Spine J. 2002; 11 Suppl 2:S198-S205.

6. Stoll TM, Dubois G, Schwarzenbach O. The dynamic neutralization system for the spine: a multi-center study of a novel non-fusion system. Eur Spine J. 2002;11 Suppl 2:S170-S178.

7. Zhu Q, Larson CR, Sjovold SG, et al. Biomechanical evaluation of the Total Facet Arthroplasty System: 3-dimensional kinematics. Spine (Phila Pa 1976). 2007;32(1):55-62.

8. Phillips FM, Tzermiadianos MN, Voronov LI, et al. Effect of the Total Facet Arthroplasty System after complete laminectomy-facetectomy on the biomechanics of implanted and adjacent segments. Spine $J$. 2009;9(1):96-102.

9. Fairbank JC, Pynsent PB. The Oswestry Disability Index. Spine. 2000;25(22):2940-2953.

10. Webb S, Brown CV, Sachs BL. Total facet arthroplasty in the treatment of spinal stenosis: reports from an ongoing IDE clinical trial. Poster presented at: 7th Annual SAS Global Symposium on Motion Preservation Technology; May 1-5, 2007; Berlin, Germany.

11. Prejbeanu R, Branea I, Vermesan D, Vermesan H, Poenaru DV, Webb S. The Total Facet Arthroplasty System (TFAS) in the treatment of lumbar stenosis: medium term clinical results on 20 cases. Poster presented at: 8th Annual SAS Global Symposium on Motion Preservation Technology; May 6-9, 2008; Miami, FL.

12. Sjovold SG, Zhu Q, Bowden A, et al. Biomechanical evaluation of the Total Facet Arthroplasty System ${ }^{\circledR}$ (TFAS $\left.{ }^{\circledR}\right)$ : loading as compared to a rigid posterior instrumentation system. Eur Spine J. 2012;21(8): $1660-1673$. 
13. Copay AG, Glassman SD, Subach BR, Berven S, Schuler TC, Carreon LY Minimum clinically important difference in lumbar spine surgery patients: a choice of methods using the Oswestry Disability Index, Medical Outcomes Study questionnaire Short Form 36, and pain scales. Spine J. 2008;8(6):968-974.

14. Okuda S, Miyauchi A, Oda T, Haku T, Yamamoto T, Iwasaki M. Surgical complications of posterior lumbar interbody fusion with total facetectomy in 251 patients. J Neurosurg Spine. 2006;4(4):304-309.

15. Weise L, Suess O, Picht T, Kombos T. Transpedicular screw fixation in the thoracic and lumbar spine with a novel cannulated polyaxial screw system. Med Devices (Auckl). 2008;1:33-39.

16. Lee CS, Hwang CJ, Lee SW, et al. Risk factors for adjacent segment disease after lumbar fusion. Eur Spine J. 2009;18(11):1637-1643.

17. Vaga S, Brayda-Bruno M, Perona F, et al. Molecular MR imaging for the evaluation of the effect of dynamic stabilization on lumbar intervertebral discs. Eur Spine J. 2009;18 Suppl 1:40-48.

18. Magureanu M, Vermesan D, Prejbeanu R, et al. Transforaminal lumbar interbody fusion (TLIF) - current concepts and development of a new implant to restore lordosis. Med Connect. 2013;8(4):45-50.

19. Niosi CA, Zhu QA, Wilson DC, Keynan O, Wilson DR, Oxland TR. Biomechanical characterization of the three-dimensional kinematic behaviour of the Dynesys dynamic stabilization system: an in vitro study. Eur Spine J. 2006;15(6):913-922.

20. Schmoelz W, Huber JF, Nydegger T, Claes L, Wilke HJ. Influence of a dynamic stabilisation system on load bearing of a bridged disc: an in vitro study of intradiscal pressure. Eur Spine J. 2006;15(8):1276-1285.
21. Delank KS, Gercek E, Kuhn S, et al. How does spinal canal decompression and dorsal stabilization affect segmental mobility? A biomechanical study. Arch Orthop Trauma Surg. 2010;130(2):285-292.

22. Kumar A, Beastall J, Hughes J, et al. Disc changes in the bridged and adjacent segments after Dynesys dynamic stabilization system after two years. Spine (Phila Pa 1976). 2008;33(26):2909-2914.

23. Schaeren S, Broger I, Jeanneret B. Minimum four-year follow-up of spinal stenosis with degenerative spondylolisthesis treated with decompression and dynamic stabilization. Spine (Phila Pa 1976). 2008;33(18):E636-E642.

24. Hoppe S, Schwarzenbach O, Aghayev E, Bonel H, Berlemann U. Long-term outcome after monosegmental L4/5 stabilization for degenerative spondylolisthesis with the Dynesys device. J Spinal Disord Tech. Epub October 16, 2012.

25. Haddad B, Makki D, Konan S, Park D, Khan W, Okafor B. Dynesys dynamic stabilization: less good outcome than lumbar fusion at 4-year follow-up. Acta Orthop Belg. 2013;79(1):97-103.

26. Schwarzenbach O, Berlemann U, Stoll TM, Dubois G. Posterior dynamic stabilization systems: DYNESYS. Orthop Clin North Am. 2005;36(3):363-372.

27. Tan JS, Bailey CS, Dvorak MF, Fisher CG, Cripton PA, Oxland TR. Cement augmentation of vertebral screws enhances the interface strength between interbody device and vertebral body. Spine (Phila Pa 1976). 2007;32(3):334-341.
Medical Devices: Evidence and Research

\section{Publish your work in this journal}

Medical Devices: Evidence and Research is an international, peerreviewed, open access journal that focuses on the evidence, technology, research, and expert opinion supporting the use and application of medical devices in the diagnosis, treatment and management of clinical conditions and physiological processes. The identification of novel

\section{Dovepress}

devices and optimal use of existing devices which will lead to improved clinical outcomes and more effective patient management and safety is a key feature. The manuscript management system is completely online and includes a quick and fair peer-review system. Visit http://www. dovepress.com/testimonials.php to read real quotes from authors. 